\title{
Preface
}

\section{Aesthetic Experience and Art}

In August 2002, the third course in a series of four Nordic $\mathrm{PhD}$ courses in aesthetics sponsored by NorFA, was held at Sandbjerg Slot, Denmark. The series was originally initiated by two doctoral students from Uppsala, Katarina Elam and Staffan Bengtsson. The courses were organised by the chairs of aesthetics in Helsinki, Uppsala, Oslo, and Aarhus. The general theme of the series was "Aesthetic Experience". The first course was held in Sweden, at Sätra Brunn in 1999, and the title was "Aesthetic Experience and the Body". The second course was held in Norway at Lysebu in 2000 and entitled "Aesthetic Experience and Interpretation". The fourth course should have taken place in Finland in 2003, but was unfortunately cancelled for technical reasons.

This third and - as it turned out - last course addressed the topic of "Aesthetic Experience and Art"; the interrelationship between aesthetics and art being the main issue. Three major perspectives were outlined, 1) the genealogy in terms of history of concept of the relationship between the concepts of "aesthetics" and "art", respectively, 2) the historical change of this interrelationship seen through the varying interpretations of it by philosophy, by general art theory, by the disciplines of the individual artforms, by cultural theory, etc., 3) the current status of the concept of art, the interrelationship between aesthetics and art theory also in the perspective of the ongoing so-called aestheticization of everyday life as such. These and other issues focusing on the extension and the interrelationship of the concepts of aesthetics and art, respectively, were to be discussed during and after lectures and workshop presentations.

As anyone involved in current aesthetic theory will know, these topics are in the very centre of attention these years. This fact may have contributed to the very intensive spirit of the conference that August. During five wonderful summer days 43 participants worked and discussed day and night, giving and listening to not less than 39 presentations and papers. The Nordic Journal of Aesthetics kindly accepted to publish nine papers, all of them written by doctoral students. The contributions will hopefully demonstrate the diversity of interest and approach at the conference - and make participating scholars recall discussions and intellectual interchange, not just in terms of lost parts of personal history, but also in terms of work in progress and work to come. 